\title{
ESPECIAL
}

\section{I - A política de estágios na ENAP}

\section{Dielai Carvalho Pereira*}

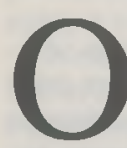

Estágio, no curso de Políticas Públicas e Gestão Governamental da Escola Nacional de Administração Pública da FUNCEP, constituirá um período de formação prática, correspondente a oito meses, em que o aluno é colocado em uma situação de trabalho, com a oportunidade de contribuir efetivamente para o desenvolvimento das atividades dos órgãos ou entidades em que estagia e de exercitar a aplicação de conceitos e técnicas de gestão.

Para entendimento mais claro dos objetivos e princípios pedagógicos dos estágios, bem como das estratégias de atribuição dos mesmos aos futuros alunos, serão levados em consideração os diferentes contextos em que se deverão realizar:

1 - Contexto da Administração Pública e da ENAP.

2 - Perfil de entrada e saída do aluno do Curso de Políticas Públicas e Gestão Governamental.

3- Quadro Institucional das Organizações em que se desenvolverão os estágios.

O período de estágio poderá ser cumprido num só local, dentro da mesma Instituição ou em vários locais. Poderá ser cumprido ainda, em Instituições de natureza diversa, ou similares, tudo dependendo das necessidades de formação identificadas para cada aluno e poderá, também, ser desenvolvido em dois momentos, com características próprias e fins específicos: um, de maior duração, e outro, um pouco menor, ambos alternadamente, envolvendo a Administração Pública, e a iniciativa privada.

Os Estágios podem ser identificados, para fins de seleção de locais, atribuição, realização, acompanhamento e avaliação, segundo três dimensões:

A primeira refere-se à área ou campo de trabalho. Do ponto de vista do órgão ou entidade, esta dimensão diz respeito ao ambiente externo à instituição e se refere às necessidades da sociedade, ou seja, aos serviços ou bens que

* Especialista em Educação, Diretor de Estágio da ENAP. produz. Refere-se, portanto, à área finalística na qual estará centrado o estágio.

$A$ segunda dimensão é constituída pelos subsistemas básicos gerenciais ou funcionais, comuns a todas as organizações e podem ser preliminarmente grupados como se segue:

- de planejamento, orçamento, captação de recursos, avaliação e controle, compreendendo objetivos, métodos, técnicas, informações e resultados;

- financeiro, referente a normas e processos de execução financeira, prestação de contas, etc.;

- de organização administrativa, abrangendo as questões de divisão de tarefas, de modernização de estruturas, de organização, métodos e técnicas administrativas;

- jurídico, referente à legisiação geral e específica;

- de dinâmica organizacional, compreendendo os problemas referentes a marketing, competição, representação, processos decisórios, estratégias de atuação, negociação, comunicação, etc.;

- de recursos humanos, em seus aspectos de recrutamento, seleção, carreira, manutenção e treinamento, enfim, desenvolvimento;

- de materiais, abrangendo patrimônio e consumo, nos seus diferentes

- de serviços gerais, compreendendo os serviços de limpeza, conservação, copa, portaria, etc.

Esses subsistemas, que permeiam todas as organizações, serão, de certa forma, comuns a todos os estágios, podendo ser objeto de análise e experimentação mais intensa, por um outro estagiário, em um ou outro subsistema. O Estágio, em qualquer subsistema, pressupõe capacidade de gestão de todos os demais.

A terceira dimensão refere-se ao tipo de organização, compreendendo seu nivel de abrangência, natureza jurídica e porte. Para efeito de identificação reconhecem-se os seguintes tipos: aspectos de administração;
1 - Administração Pública Direta, compreendendo os niveis federal, regional, estadual e municipal, além dos respectivos Conselhos.

2- Administração Pública Indireta, compreendendo as Autarquias, as Fundações, as Empresas Públicas $\mathrm{e}$ as Sociedades de Economia Mista.

3 - Empresas privadas, observadas quanto à formação e tamanho de seu capital.

4 - Sociedades Civis - Entidades Sociais, principalmente as filantrópicas, as culturais, as recreativas e as de classe.

5- Os Organismos Internacionais.

Essa dimensão identificará, portanto, os estágios quanto ao grau de complexidade e objetivos das Instituições.

Considerando o inédito da experiência institucional brasileira, ao criar o Curso de Políticas Públicas e Gestão Governamental, procurar-se-á, anualmente, definir linhas prioritárias de atuação da ENAP para fins da atribuição dos Estágios. Esta definição decorrerá das prioridades de Governo, de solicitações expressas por órgãos ou setores articulados com a ENAP ou de problemas específicos identificados nas pesquisas e diagnósticos realizados pela própria Escola.

As linhas de atuação poderão enfatizar qualquer das dimensões referidas sem, entretanto, perder de vista a interdependência delas e o caráter Institucional dos estágios.

Os Estágios definidos nas linhas prioritárias de atuação poderão se desenvolver segundo metodologia específica resultando em projetos de ação expressamente dirigidos para formulação, implementação e avaliação de políticas públicas. A operacionalização desses projetos de ação será integrada ao ensino e à pesquisa.

A atribuição dos locais de estágio será feita pelo Diretor-Geral da Escola, mediante indicação do Diretor de Estágios. Nessa proposição, serão levados em conta os seguintes fatores:

$$
\begin{aligned}
& \text { - interesses, aspirações e projetos do } \\
& \text { aluno; } \\
& \text { - condições pessoais, tais como ida- } \\
& \text { de e situação familiar; } \\
& \text { - experiência e estudos anteriores; }
\end{aligned}
$$




\section{ESPECIAL}

- personalidade e aspectos que devem ser aperfeiçoados;

- características da instituição em que se darão os estágios;

- competência profissional e características individuais do orientador de estágios;

- interesses do Governo e da Escola;

- disponibilidades de locais a cada ano.

A combinação desses fatores será objeto de ação da Diretoria de Estágios. Para tanto, procederá a entrevistas com os alunos, e desenvolverá, de maneira sistemática, um levantamento das Instituiçōes que devem, a cada ano, receber estagiários.

Na seleção dos locais, a Direção de Estágios levará em conta os seguintes critérios:

1 - Os interesses da Instituição em trabalhar nas linhas prioritárias de atuação da ENAP e colaborar para o alcance de seus objetivos.

2 - Conceito da Instituição, no que se refere à estabilidade econômica ou qualidade dos serviços que presta.

3 - Importância e abrangência da Organização, tendo em vista o alcan- ce dos objetivos nacionais e a formulação, implementação e avaliação de politicas públicas.

4 - Relevância do padrão tecnológico que utiliza, tendo em vista prioridades estratégicas de desenvolvimento.

5 - Possibilidades oferecidas quanto à diversificação de experiências do estagiário.

$\mathrm{Na}$ seleção das Instituições, também se levará em conta o cargo, o nivel, e as características da pessoa designada como ORIENTADOR DO ESTÁGIO.

O ORIENTADOR DE ESTÁGIO será escolhido dentre pessoas que apresentem as seguintes características:

- conhecer toda a organização e, razoavelmente, sua história, evolução, periodos significativos, políticas e estratégias de atuação;

- conhecer a problemática da organização, ou seja, o sistema competitivo e o seu ambiente externo, as leis e as normas que restringem ou estimulam a sua atuação;

- interessar-se pelos seus auxiliares, no que diga respeito ao crescimento profissional, aperfeiçoamento de caráter, conduta, desempenho, etc:

- estar disposto a dedicar parte de seu tempo útil, estimado entre 3 a 5 horas semanais, durante oito meses, na orientação do estagiário, desenvolvendo com ele uma relação do tipo Mestre-Aprendiz;

- estar aberto para receber sugestões quanto a possíveis medidas para melhor desempenho da sua Organização.

Estas idéias consubstanciam a proposta inicial para o desenvolvimento da política de estágio da ENAP.

Todas as colocaçōes feitas exigirão aprofundamentos, desdobramentos e operacionalizações, levando em conta, sempre, as características da formação práti$\mathrm{ca}$, presente na idealização da Escola $\mathrm{Na}$ cional de Administração Pública.

Por se tratar de uma experiência inédita, a ENAP se enriquecerá com as vivências individuais e institucionais brasileiras, quer na confecção e formulação do Curso de Políticas Públicas e Gestão Governamental, quer na implementação da política de estágios.

Eis uma proposta aberta, inovadora e acolhedora de contribuições que venham aprimorá-la.

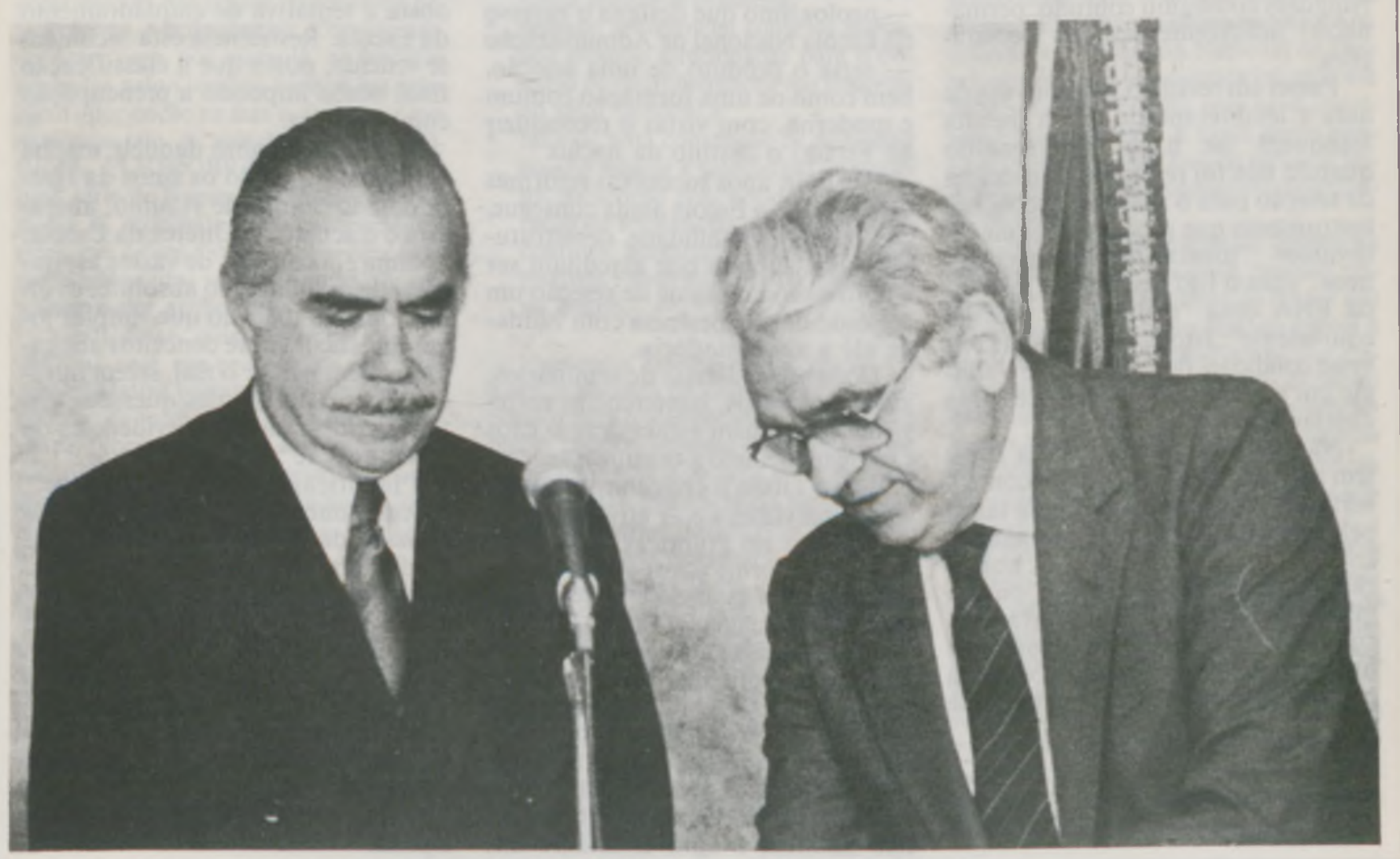

